\title{
Conflict resolution in meta-organizations: the peculiar role of arbitration
}

\author{
Klaus Heine ${ }^{1,2^{*}}$ and Maximilian Kerk ${ }^{1}$
}

\author{
*Correspondence: heine@laweur.nl \\ 1 Erasmus Universiteit Rotterdam, \\ Rotterdam, Netherlands \\ ${ }^{2}$ Jean Monnet Chair of Economic \\ Analysis of European Law, \\ Rotterdam, Netherlands
}

\begin{abstract}
Meta-organizations, such as joint ventures and other complex forms of inter-firm organizations, are characterized by the absence of formal authority. This lack of internal hierarchy can lead to severe conflicts between cooperating organizations and hence requires specific governance. This paper recognizes arbitration as an integral part of the organizational architecture of meta-organizations. First, attributes are identified that in the context of meta-organizations distinguish arbitration from ordinary courts. Then these attributes are considered to discuss why arbitration should be understood as an internal rather than an external governance device, delineating the boundaries of meta-organizations, and leading to optimal investment decisions.
\end{abstract}

Keywords: Meta-Organizations, Arbitration, Conflict resolution, Organizational

boundaries

\section{Introduction}

In recent years commercial arbitration has become increasingly popular as a means of dispute resolution between business partners, especially in an international context. The ever growing importance of commercial arbitration has been accompanied by a shift in the organizational structure of business forms from mainly large corporations and conglomerates towards more flexible inter-organizational arrangements that contractually mirror the specific task of the cooperation (Ménard 1996; 2013; Baker et al. 2008). Examples are the joint construction of an oil platform and other infrastructure projects, or the development of new complex technologies such as software or pharmaceuticals. In these types of ventures the partners pool their specific capabilities, in order to mutually exploit their strategic interdependency (Gulati 1995; 1998; Argyres and Mayer 2007).

The typical legal forms of these business agreements are joint ventures and industry consortia, but even more complex legal arrangements are possible (Oxley and Silverman 2008). Despite their various legal forms, all these organizational arrangements consist of legally autonomous organizations and hence can be classified as meta-organizations (Gulati et al. 2012). ${ }^{1}$ Meta-organizations do not usually have a formal, internal authority because the assets are jointly owned by the participating parties. Thus, no party individually holds the residual right of control. As a consequence, no single party has exclusive authority to determine the use of the assets (Hart 1995, 30).

In the absence of effective governance, meta-organizations are vulnerable to holdups by individual parties, which can impede fruitful cooperation (Klein et al. 1978). An

(c) The Author(s). 2017 Open Access This article is distributed under the terms of the Creative Commons Attribution 4.0 International License (http://creativecommons.org/licenses/by/4.0/), which permits unrestricted use, distribution, and reproduction in any medium, provided you give appropriate credit to the original author(s) and the source, provide a link to the Creative Commons license, and indicate if changes were made. 
obvious solution to prevent hold-ups is vertical integration, in which the decision rights are allocated to the most important party involved into the venture. But in situations in which the investment decisions of all participating parties are equally important, vertical integration faces a problem. The vertical decision making structure deprives the integrated party of the optimal investment incentive (Grossman and Hart 1986; Hart and Moore 1990). Therefore, alternative governance structures and elaborated contract designs are necessary to prevent parties from holding each other up (Schanze 1993; Gibbons 2005; Argyres and Mayer 2007). This, in turn, requires a conflict resolution mechanism that is able to enforce the formal and non-formal parts of the contract.

Essentially, arbitration works as a governance device that overcomes the need to transform a meta-organization into a single firm, allowing parties to benefit from (knowledge) specialization and the more targeted investment incentives vested in a semi-integrated organizational structure. One may argue that arbitration is a "contracting institution" that can constitute a comparative advantage against other contractual arrangements when the coordination of specific assets is center stage (Casella 1996; Antràs 2014). In particular, it can be argued that arbitration creates and sustains an organizational architecture that allows for contingent investment levels by the owners into the meta-organization. Even though the arbitrator does not have any property rights, he has the competence to ultimately execute the residual right of control and to allocate the residual right of income. Unlike in an ordinary court, an arbitrator is able to do so because he can be understood as an integral part of the architecture of the meta-organization who can observe and assess the investments of the cooperating parties.

More concretely, the arbitrator creates additional incentives for the parties to invest by inducing a surplus-seeking contest. This means that he rewards higher investment levels with a greater share of the surplus of the joint activity. As a consequence, the parties will compete for the surplus by increasing their investment. Yet, this investment promotion faces the risk of over-investment. For that reason the arbitrator has to sensibly set the contest incentives in order to balance the problem of under-investment with the risk of over-investment. That means that the stake holding parties, already at the stage of setting-up the meta-organization, have to make deliberate decisions not only on specific arbitration clauses but also concerning which arbitration court should resolve a possible future conflict. Arbitration thus already takes a role in the organizational architecture at the nascent state of a meta-organization. In a later stage, it can reveal its balancing effect on investment decisions.

The paper will first present four cases in which arbitration courts took a pivotal role in the organizational architecture of meta-organizations to resolve conflicts (Section Arbitrated governance). This will serve as a background to illustrate our discussion concerning the applicability of different concepts of the theory of the firm, and the challenges these concepts face in the wake of meta-organizations (Section Meta-organizations, conflict and the theory of the firm). In Section A formal view on arbitration in meta-organizations we will present a formal model to target the specific aspects of the governance problem that meta-organizations face. It turns out that ease of enforcement, latitude, information access and fast decision making are key parameters to make metaorganizations viable over time, and that arbitration courts have a comparative advantage over other conflict resolution mechanisms in achieving these goals. In Section Arbitration and the boundaries of meta-organizations we will discuss our insights and argue 
that arbitration is a means to define and to protect the boundaries of meta-organizations. Section Conclusion concludes.

\section{Arbitrated governance}

Because of its private nature, the results of arbitrated disputes in meta-organizations are usually not published. This makes it nearly impossible to provide a comprehensive empirical overview of those disputes. Nevertheless, certain cases with specific relevance for the development of arbitration case law have been published anonymously. Here four of those cases will be presented. They fall into two broad categories: On the one hand conflicts about the distribution of the surplus (profit or other benefits) that the joint venture had produced and on the other hand disagreement about the contributions a party made to the joint venture. Each example concludes with the arbitrator's decision and his characteristics as third party decision maker. These characteristics will then serve in a stylized manner as a basis for the formal analysis.

In the 2013 case Mother company of joint venture corporation shareholder (US) v. venture corporation shareholder (Mexico) the main cause of dispute was disagreement over the distribution of the profit of the joint venture. ${ }^{2}$ The claimant $(C)$ and the respondent (R) engaged into a joint venture for the operation of C's warehouse stores in Northwest Mexico. Each party held a 50\% ownership share.

The profits were almost entirely re-invested and hence the joint venture did not produce an accumulated, single surplus until 15 years after the joint venture was founded, when the dispute arose. $\mathrm{R}$ desired the distribution of the accumulated profit, whereas $\mathrm{C}$ disagreed. $\mathrm{R}$ then removed the director of operations, a former employee of $\mathrm{C}$, and called for a shareholder meeting to "decide on the distribution of dividends". ${ }^{3}$ This meeting ended in a deadlock between $\mathrm{C}$ and $\mathrm{R}$ and triggered further negotiations about the distribution of the joint venture's surplus.

In the course of these negotiations regarding the profits distribution, $\mathrm{R}$ filed a case at a local court attempting to force a distribution of the surplus. Through the court decision, $\mathrm{R}$ acquired the payment of its dividends, according to Mexican company law. In response $C$ started arbitration proceedings against $R$, arguing that $R$ violated the contractual mechanisms for resolving a deadlock. The arbitrator followed the argumentation of $\mathrm{C}$ and ordered $\mathrm{R}$ to repay the dividends to restore the joint venture's financial status. With this award the arbitrator enforced the surplus sharing rule that the parties had agreed on at the foundation of the joint venture.

In the 2006 case Limited Liability Company (Bahrain) v. Establishment (Saudi Arabia) the main cause of dispute was the respondent's failure to provide balance sheets for the joint venture, and the resulting ambiguity about its financial state. ${ }^{4}$ The claimant $(\mathrm{C})$, a limited liability company from Bahrain, and the respondent (R), the owner of a Saudi Arabian Establishment, engaged into a joint venture for the operation of R's establishment. $C$ held a majority of the ownership shares and hence was appointed as the manager of the joint venture, but the de facto management was with $R$.

In $2002 \mathrm{R}$ violated its obligation to report the joint venture's financial situation in terms of the provision of balance sheets. $C$, subsequently, alleged that $\mathrm{R}$ had attempted to embezzle the joint venture's surplus and hence invoked arbitration proceedings. The arbitration court applied expert knowledge in order to survey the financial and contractual situation of the joint venture to verify the allegations. As a result of the expert's 
investigations, the arbitrator decided in favour of C SAR 17, 746,462 and against R. By applying the expert's knowledge, the arbitrator verified the joint venture's surplus and enforced its intended sharing.

In the 1996 case Construction Company v Construction Company the dispute concerned disagreement over the beneficiary of two Export Incentive Certificates issued by the Turkish state. ${ }^{5}$ The claimant (C), a US construction company, and the respondent (R), a Turkish construction company, entered into a joint venture for a construction project for a Turkish authority. Each party held a 50\% ownership share.

Before and shortly after the foundation of the joint venture, two "Export Incentive Certificates" (EIC) were issued by the Turkish state to R. These EICs granted the holder benefits that related to the activities of the joint venture and therefore counted towards its surplus. Six years after the establishment of the joint venture R sought payment of a share of the surplus concerning the EICs' benefits. Due to the ownership structure, no decision regarding the sharing was reached in the board of the joint venture. As a result, $R$ issued a "leadership decision"6 that granted itself the entire share of the surplus that was generated by the EICs' benefits. Hereupon, $\mathrm{C}$ called for arbitration, claiming that it was agreed in the joint venture agreement that the benefits of the EICs were to be enjoyed by the joint venture. $\mathrm{R}$ replied that Turkish law prohibits benefits derived from EICs to be shared with foreign entities.

In his decision the arbitrator differentiated between tax benefits and savings derived from EICs. Since different legal regimes apply, the stipulations in the joint venture agreement apply and hence the joint venture is entitled to these benefits. By applying his expert knowledge in legal, contractual and financial aspects, the arbitrator defined and delimited the joint venture's surplus and enforced the contracted sharing rule.

In the case First Investor, in liquidation (EU country), Second Investor (EU country) v Ministry of Agriculture (Non-EU country) the dispute concerned a failure by the respondent to contribute adequately to the joint venture. ${ }^{7}$ The claimant $(C)$ and the respondent (R) entered into a joint venture for the cultivation of agricultural products and breeding of livestock, as well as their sales and distribution. The joint venture agreement stipulated that $\mathrm{C}$ contributes with funding and that $\mathrm{R}$ contributes with land, workforce, equipment and facilities. Moreover, it was agreed that the joint venture would stop operations if it would be not profitable for a five years period (cease agreement).

From the beginning the joint venture had difficulties starting operations mainly because the land was only partially cultivated due to property conflicts with sedentary farmers, a lack of available workforce, protests and insufficient office space. Therefore, the joint venture was producing losses over the first years. In the course of an outbreak of a conflict in a neighboring country, $\mathrm{R}$ asked $\mathrm{C}$ if part of the joint venture's land could be used by an international organization to host refugees. $C$ agreed to this request that the international organization could use "a particle". 8 Thereupon, $\mathrm{R}$ made the whole land available for the international organization. Because accommodation facilities were established on the land by cementing the surface, a vast effort would be required to restore the land for agricultural production.

As a result, $C$ rejected further financial contributions to the joint venture and demanded its liquidation according to the initial cease agreement by invoking arbitration proceedings. The arbitrator examined the claim that $\mathrm{R}$ had failed to fulfill its contribution obligations. As a result of his verification of the contributions to the joint venture, 
the arbitrator determined that $\mathrm{R}$ had failed its contribution duty. Therefore, the arbitrator ordered the dissolution of the joint venture and awarded $\mathrm{C}$ damages to the amount of its financial contributions. In his role as third party decision maker, the arbitrator verified the parties' contributions and concluded this in the final award.

\section{Meta-organizations, conflict and the theory of the firm}

Classical organizations emerge as a hierarchy of individuals and build upon employment relationships, which formally define power and authority. Meta-organizations may also employ workers and managers at a production site, but it is not the employment relationship as such which characterises this type of organization. It is rather the complex corporate contracting that provides the resources for the provision of services and production. As a consequence meta-organizations lack to a large degree the typical hierarchical organization of power in classical organizations. Meta-organizations are either characterized by the absence of formal authority at all or formal authority plays out through complex contractual networks (Gulati et al. 2012).

In the absence of a formal authority on the top of the organizational architecture, the individual interests of each corporate member can impair or even block the decisionmaking process in the meta-organization (Lumineau et al. 2015; Ahrne and Brunsson 2005). Conflict areas such as the coordination of efforts or the distribution of benefits can potentially deadlock the whole decision-making process. To prevent that infighting between the members which deadlocks the meta-organization, an organizational architecture is required that resolves internal disputes by means of external enforcement (Lumineau and Oxley 2012). That means keeping the meta-organization as such viable, without converting it into a classical monolithic organization. Thereby it can be assumed that a private dispute resolution mechanism - an arbitrator - has multiple advantages over calling for a decision from a public court. In particular, an arbitrator is not bound by national laws, which may provide strict procedural rules or are limited in jurisdiction (see Benson 1999; Craig et al. 1990). In addition, a private arbitrator has typically more expert knowledge and hence is better equipped to observe and assess the contributions of a meta-organization's members. This is because private third party decision makers are not only legal professionals but often also experts in the respective industry of their assignment. These industry experts hold business and technical knowledge that helps to better understand the circumstances of the dispute and to provide a timely and adequate resolution. Moreover, the high confidentiality of alternative dispute resolution increases the parties' willingness to share sensitive business information, and this improves the third party's access to relevant information (see Stipanowich 2004, 846). Finally, confidentiality allows the involved parties to maintain the meta-organization's external image and reputation, which might be negatively affected by a revelation of the internal dispute (for a discussion see Noussi 2010).

Highlighting these advantages of arbitration for internal dispute resolution in metaorganizations, raises the question of whether this governance mechanism should be considered as external or internal to the organization. All the mentioned attributes, access to the internal information, authority for decision making, and privacy, are very similar to the features of internal governance mechanisms such as the board of directors in a regular company. Moreover, decision awards of the private third party ultimately rely also on enforcement by ordinary courts, just like any other internal governance mechanism 
has to be backed by the external public governance system (Aguilera et al. 2015). To substantiate this conceptual placement of third party decision making within the boundaries of meta-organizations, it seems beneficial to test it against the firm boundary concepts of incumbent theories of the firm.

Understanding inter-firm collaboration as a meta-organization is not the first attempt to elaborate on the determination of the boundaries of the firm. Williamson (1991) uses the term hybrid organization to discuss this distinct type of governance structure that lies between market and hierarchy. His starting point is that organizations have to adapt to changing situational contexts, in order to survive, and that organizational types vary in their capacity to adapt accordingly. He distinguishes between two types of adaptation, autonomous and cooperative, which are mirrored in the two generic governance structures of market and hierarchy. In particular, in the governance mode 'market' autonomous adaptation works best to address changes, whereas in 'hierarchy' cooperative adaptation is most efficient. The hybrid organization, as a combination of market and hierarchical features, has the advantage of being reasonably suited to tackle both types of adaptations. As a result, the concrete situational context determines which governance mode is the most suitable to keep an organization viable. In principle there is a whole continuum of situational contexts which are reflected in a continuum of organizational structures between markets and hierarchies. A meta-organization would develop from this perspective as a reflex to certain market conditions.

The New Property Rights theory is especially elaborative on the implications of the two polar transaction structures market and hierarchy. In a system of integrated ownership the owner can selectively replace certain workers and assets from the production process, whereas in a market transaction only the counterparty as a whole can be replaced; thus in the latter case the decision is only binary. Following this, the boundaries of the firm are defined by the integrated ownership of productive assets which are controlled by a single entity. Applying this boundary criteria to meta-organizations would draw the firms' boundaries around the individual entities and qualify the transactions within the meta-organization as market transactions. Accordingly, dispute resolution by arbitration would have to be considered as external governance which is a sheer substitute to ordinary courts. This consideration reveals that the very stringent classification of ownership is not very appropriate to investigate the boundaries of meta-organizations. Since the New Property Rights theory focuses exclusively on the power vested in property rights, it cannot accommodate meta-organizations which are characterized by the absence of formal authority and the non-integration of property rights. The reflection about the architecture of meta-organizations is not only important for the background of the growing number of this type of organizations, but it also gives strong impulses for a deeper analysis of what a firm is. In particular it adds to the analysis of what is meaningful power in the theory of the firm. Or, to use a phrase of Conner $(1991,139)$ : a theory of the firm must deal simultaneously with the issue of opportunism (the firm as "avoider of a negative") and the issue of value creation or innovation (the firm as the "creator of a positive"). Thus, dealing with the subject of meta-organizations requires a deep reflection about the boundaries of the firms in a dynamic setting, meaning that an answer must be given for the existence of a specific firm structure as well as its boundaries and internal organization. ${ }^{9}$

The boundary problem is further seized upon by Zingales (2000). He argues that the incumbent theories of the firm are certainly a necessary foundation for a principal 
understanding of firm organization. However, over the years the traditional approaches towards a theory of the firm have lost their predominance as the standard role model for the more complex organizational structures. In the modern distributed economy the boundaries of the firm have become fuzzy and "the major corporate governance problem has become how to prevent conflicts among stakeholders from paralyzing or destroying the firm." (Zingales 2000, 1648) Therefore, a sensible balance between the different actors in an organization and especially between their de jure and de facto control power is crucial (see also Rajan and Zingales 2000a,b). These functions, for balancing the diverging powers and for avoiding opportunism in a meta-organization, are exactly what arbitration does. It induces a level of joint investments that aims at preventing under- and overinvestment. In the following section we will dig deeper into the mechanism with which the arbitrator nudges the parties towards optimal investments.

\section{A formal view on arbitration in meta-organizations}

Because of the absence of formal authority in a meta-organization, infighting between the members over the profits might arise. This conflict potential is likely to be anticipated by the members, with the result that they may withhold critical resources or more generally devote less effort to the meta-organization. Because of these reduced efforts, the metaorganization underperforms and the members miss out on potential profits. To attain these profits the design of the meta-organization can include a governance mechanism to internally solves conflicts between the members. For this internal dispute resolution the design can stipulate an arbitrator who has the power to form a decision to settle the conflict.

This dispute resolution requires two attributes to be feasible. Firstly, decisions of the arbitrator must be enforceable, comparable to the board of directors of a classical organization. An arbitration court, as an example, issues an award that is enforceable in ordinary court according to the Convention on the Recognition and Enforcement of Foreign Arbitral Rewards ("New York Convention" from 1958). Secondly, the arbitrator must be able to observe internal information of the meta-organization, such as the members' effort levels. If this is not the case, the third party has not the necessary information to reach an appropriate decision. If these two characteristics are met by the arbitrator, then he is able to resolve conflicts within the meta-organization by issuing a binding decision award.

To illustrate this role of the arbitrator this section employs a model of collaborative production with imperfect contracting. For a meta-organization, a joint venture between two parties is assumed and the effort levels are represented by the investments in the joint venture. In a first step the joint venture with a unanimous sharing rule is illustrated. Then an arbitrator is introduced who is able to observe the investment levels and who allocates the shares of the surplus by the means of a contest. Since this allocation is enforceable in court, the arbitrator's decision marks the parties' outside option and hence their bargaining power over the surplus.

Consider two firms A and B, who jointly found a joint venture. The joint venture is in possession of a productive asset. Because of this ownership structure A and B jointly own the asset and, consequently, either of them can veto its use. In order to make use of the asset, $\mathrm{A}$ and $\mathrm{B}$ need to make relation-specific investments $a$ and $b$ in period 1 , which cannot be contracted ex ante for two reasons (see Fig. 1). Firstly, the production function is unknown at $t=0$, which means that no party knows the optimal levels of investment 


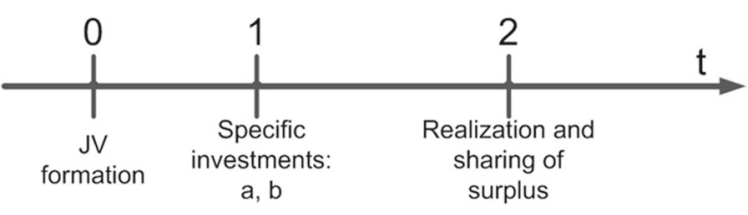

Fig. 1 Timeline of the model

ex ante. Secondly, while at $t=2$ investment levels can be observed by the parties of the joint venture, they cannot be verified externally by a court. As a result, courts cannot enforce the contract of the joint venture. Since it is not possible to contract and to enforce specific investment levels, the governance structure of the joint venture has to set the proper incentives in order to stimulate efficient investment levels.

In period 2 the joint venture produces a surplus according to a production function $F(a, b)$ which is continuously differentiable, concave in the investment levels and satisfies:

$$
F(0,0)=0, \quad \frac{\partial F}{\partial x}>0, \quad \frac{\partial^{2} F}{\partial x^{2}}<0 \quad \forall x \in\{a, b\}
$$

Furthermore, it is assumed that the investments of both parties are equally efficient:

$$
\frac{\partial F}{\partial a}=\frac{\partial F}{\partial b} \quad \forall a=b \in[0, \infty)
$$

Given these assumptions there exists a first-best investment level $a^{\mathrm{FB}}, b^{\mathrm{FB}}$ that maximizes the overall surplus $F(a, b)-a-b$, which satisfies:

$$
\frac{\partial F}{\partial a^{\mathrm{FB}}}=\frac{\partial F}{\partial b^{\mathrm{FB}}}=1
$$

The two parties' individual payoffs are described by the following functions:

$$
\begin{aligned}
& \pi_{A}(a)=z(a, b \mid g) F(a, b)-a \\
& \pi_{B}(b)=(1-z(a, b \mid g)) F(a, b)-b
\end{aligned}
$$

Thereby $z(a, b \mid g)$ describes the rule for sharing the joint surplus, which is determined by Nash bargaining. The outside options for the parties, namely the payoff in case of disagreement, depend on the form of governance $g$, which can be either unanimous sharing $(g=$ US) or determination by an arbitrator $(g=$ AR).

\section{Unanimous surplus sharing}

In the baseline scenario without reliance on an arbitrator the joint venture lacks a formal internal authority and hence decisions can only be reached collectively. This collective control is due to the fact that both parties own the joint venture jointly and hence either one of the parties can veto decisions regarding its surplus. Because of the absence of formal authority and the consequential veto power, each party is able to block the profit distribution in case of disagreement. Consequently, a consensus is required for the implementation of a sharing rule. This implies that the parties' outside options in the bargaining stage are zero. Accordingly, this simple two-person Nash-bargaining without outside options (at $\mathrm{t}=2$ ) leads to an equal sharing of the surplus (see Additional file 1):

$$
z(a, b \mid \mathrm{US})=0.5
$$


Given this sharing rule each agent only takes into account the marginal effect on his own profit when he chooses his investment level (see Additional file 1):

$$
0.5 \frac{\partial F}{\partial a^{\mathrm{US}}}=0.5 \frac{\partial F}{\partial b^{\mathrm{US}}}=1
$$

Notice that the left-hand side of Eq. (7) describes the marginal benefits whereas the right-hand side describes the marginal costs of investing. Since the marginal costs in the first best solution are identical, the marginal benefits of the first order conditions of both (3) and (7) can be equalized:

$$
\begin{aligned}
& 0.5 \frac{\partial F}{\partial a^{\mathrm{US}}}=\frac{\partial F}{\partial a^{\mathrm{FB}}} \quad \Longrightarrow \quad \frac{\partial F}{\partial a^{\mathrm{US}}}>\frac{\partial F}{\partial a^{\mathrm{FB}}} \\
& 0.5 \frac{\partial F}{\partial b^{\mathrm{US}}}=\frac{\partial F}{\partial b^{\mathrm{FB}}} \quad \Longrightarrow \quad \frac{\partial F}{\partial b^{\mathrm{US}}}>\frac{\partial F}{\partial b^{\mathrm{FB}}}
\end{aligned}
$$

Given this assumption (1), the investment levels will be below the first-best solution:

$$
\begin{aligned}
& a^{\mathrm{US}}<a^{\mathrm{FB}} \\
& b^{\mathrm{US}}<b^{\mathrm{FB}}
\end{aligned}
$$

Proposition 1 The application of unanimous surplus sharing leads to an underinvestment by the joint venture's parties in comparison to the first-best solution.

\section{Introducing arbitration}

With a unanimous sharing rule the parties' outside options are zero in a dispute over the surplus. Therefore, the Nash bargaining in $t=2$ between the two parties will lead to an equal sharing. However, this sharing rule means that the parties profit from the marginal product of their investments only partially. Because of this limitation in benefit of their investments' marginal products, the parties' incentives to invest are weaker than in the first-best solution. This incentive issue causes an under-investment in the joint venture.

An arbitrator can remedy this under-investment problem by making the parties' outside option contingent on their investment levels. Therefore, it is assumed that the arbitrator is able to observe the individual investment levels in the same manner as the joint venture's parties do in $t=2$. This contingency allows the parties to improve their outside option (i.e. their payoff in case of disagreement) by investing and accordingly sets an additional incentive to invest. This means that, whereas under unanimous sharing the incentive to invest is only provided by the internalized share of the marginal product of investment, the investment incentive under arbitration governance is twofold: on the one hand the share of the marginal product that is internalized and on the other hand the prospect of improving payoff in the event of disagreement during the Nash bargaining stage.

The outside option stimulates higher levels of investment because in the case of a dispute the arbitrator decides about the distribution of the surplus. Since the arbitrator does not know the optimal levels of investment, he is bound to reward higher investments only. Applying the rule - the more a party invests, the higher will be his share of the surplus (12) - the arbitrator makes use of his ability to observe individual investment levels. Thus, by basing his distribution on the investment levels of the parties, the arbitrator creates a contest for the surplus of the joint venture that sets additional incentives to invest. These additional incentives emerge because investing is the means to compete in this 
surplus-seeking contest. Because the outside options determine the sharing in a Nash bargaining and because the arbitrator distributes the whole surplus, the factual sharing rule $z(a, b \mid \mathrm{AR})$ will be directly assigned by him even if no dispute arises. ${ }^{10}$ This underscores the fact that the role of the arbitrator in the organizational design of a meta-organization is not only to resolve a conflict at the end of a business relationship, but to add to the sustainability of the meta-organization over time.

$$
\frac{\partial z}{\partial x}(a, b \mid g=\mathrm{AR})\left\{\begin{array}{l}
>0 \text { if } x=a \\
<0 \text { if } x=b
\end{array}\right.
$$

While other views on dispute resolution usually emphasize the wasteful activities of the contest, such as litigation costs (c.f. Schweizer 1989), this analysis concentrates instead on a non-wasteful means of competition, namely the level of investment. To increase his outcome of the contest, each party has to raise his level of investment. This rise signals greater productivity to the decision maker, who, consequently, awards a greater share of the surplus to the respective party. Therefore, investing has two positive consequences for the parties' payoffs. Firstly, it increases their share of the surplus and secondly, it simultaneously increases the joint venture's surplus itself. Because of this instrument of competition, the efforts exerted in the contest are not wasteful but increase the contest's prize: the surplus of the joint venture (c.f. Chung 1996).

Moreover, the arbitrator is by assumption not biased towards any party. Because of that, he awards the same share of the surplus to each party if the investments are equal:

$$
z(a, b \mid g=\mathrm{AR})=0.5 \quad \text { if } a=b
$$

The following general Tullock contest success function satisfies these conditions (Hirshleifer 1989; Skaperdas 1996):

$$
z(a, b \mid g=\mathrm{AR})=\frac{a^{m}}{a^{m}+b^{m}}
$$

The mass effect parameter $m$ describes the shape of the sharing rule in relation to the relative investments of the two parties. Figure 2 illustrates this for the investment of A relative to a given investment of $\mathrm{B}$. The mass effect parameter indicates the elasticity of the arbitrator's decision, which is at the point of equal investment $(a=\bar{b})$ (see Additional file 1):

$$
\varepsilon_{z}=\frac{m}{2}
$$

If $m$ is very small (e.g. 0.1), then the third party's decision is very inelastic. This means, that the arbitrator departs only marginally from a 50:50 sharing of the surplus even if the investment levels differ dramatically and hence the contest sets only limited additional incentives to invest. ${ }^{11}$ On the contrary, if $m$ is very large, then the elasticity of the arbitrator's decision is very high. High decision elasticity indicates that the third party significantly alters the division of the surplus even if there are only minimal differences in the investment levels. Thus, high decision elasticity implies that the contest provides strong additional investment incentives. Because of this relation between the mass effect parameter and the decision elasticity, it determines the intensity of the investment incentives that the contest creates. Therefore, the mass effect is an important parameter for the decision maker to set in order to balance the investment incentives of the joint venture. 

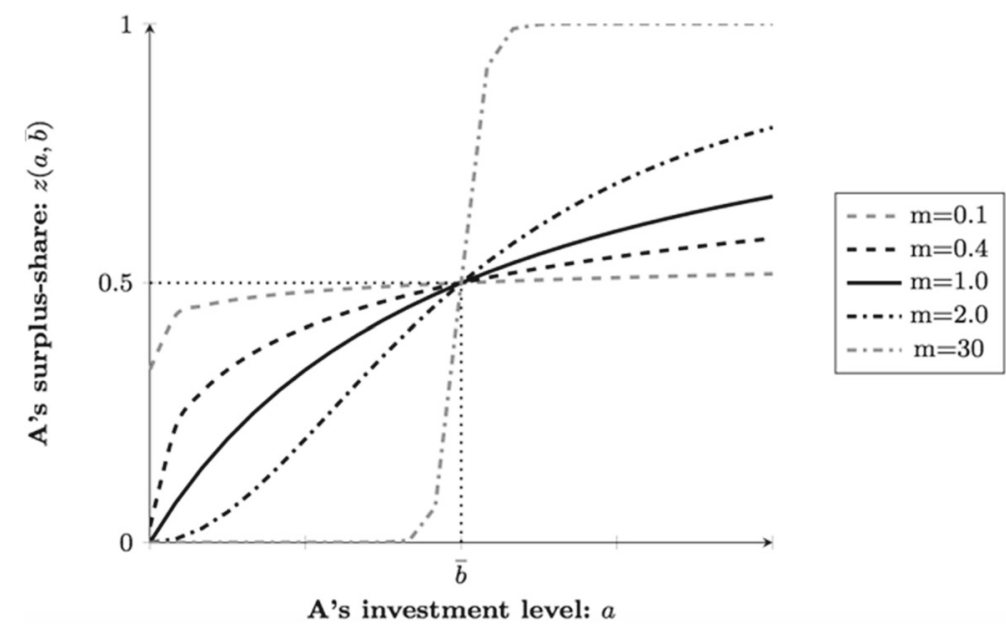

Fig. 2 Mass effect parameter and decision elasticity

Including the arbitrator's sharing rule into the two parties' individual profit functions $(4)+(5)$ and maximizing these by choosing the investment levels, leads to the following optimality conditions (see Additional file 1):

$$
\begin{aligned}
& \frac{m a^{m-1} b^{m}}{\left(a^{m}+b^{m}\right)^{2}} F(a, b)+\frac{a^{m}}{a^{m}+b^{m}} \frac{\partial F}{\partial a}=1 \\
& \frac{m a^{m} b^{m-1}}{\left(a^{m}+b^{m}\right)^{2}} F(a, b)+\frac{b^{m}}{a^{m}+b^{m}} \frac{\partial F}{\partial b}=1
\end{aligned}
$$

Giving symmetry assumption (2), the investments of both parties are equally productive and hence both parties will face symmetric objective functions. Because of this symmetry both parties will invest the same amount in equilibrium $(a=b)$. Therefore, Eqs. (16) and (17) simplify to:

$$
\frac{m}{4 a} F(a)+\frac{1}{2} \frac{\partial F}{\partial a}=1
$$

Solving for the marginal investment $\frac{\partial F}{\partial a}$ leads to:

$$
\frac{\partial F}{\partial a}=2-\frac{m}{2 a} F(a)
$$

From (7) it is known that for unanimous surplus sharing the investment level is such that $\partial F / \partial a^{N}=2$. Plugging this result into (19) allows a comparison of the investment level under third party decision making and unanimous surplus sharing:

$$
\frac{\partial F}{\partial a}=\frac{\partial F}{\partial a^{\mathrm{US}}}-\frac{m}{2 a} F(a)
$$

If a non-zero level of investment is assumed then any $m \in(0, \infty)^{12}$ means that $\partial F / \partial a<$ $\frac{\partial F}{\partial a^{\mathrm{US}}}$. Accordingly, it can be concluded given assumption (1) that the investment levels 
will be higher with third party decision making than with unanimous surplus sharing $\left(a>a^{\mathrm{US}}\right.$ and $\left.b>b^{\mathrm{US}}\right)$.

Proposition 2 If the arbitrator sets the sharing rule with a non-zero mass effect parameter $m$, then arbitration governance induces additional investment incentives which increase the investment above the level of a unanimous surplus sharing rule.

Equalizing Eqs. (3) and (18) gives the condition under which arbitration governance induces first-best investment:

$$
\frac{m}{4 a^{\mathrm{FB}}} F\left(a^{\mathrm{FB}}\right)+\frac{1}{2} \frac{\partial F}{\partial a^{\mathrm{FB}}}=\frac{\partial F}{\partial a^{\mathrm{FB}}}
$$

Solving for $m$ :

$$
m=2 \frac{\partial F}{\partial a^{\mathrm{FB}}} \frac{a^{\mathrm{FB}}}{F\left(a^{\mathrm{FB}}\right)}=2 \times \varepsilon_{F, a^{\mathrm{FB}}} \quad \leftrightarrow \quad \varepsilon_{F, a^{\mathrm{FB}}}=\frac{m}{2}=\varepsilon_{z}
$$

Where $\varepsilon_{F, a^{\mathrm{FB}}}$ describes the investment elasticity of production. It can be concluded, accordingly, that to achieve the first-best investment levels the investment elasticity of production must be equal to the third party's decision elasticity. Therefore, the sharing rule under arbitration governance should be set in such a way that the elasticity of the sharing rule is equal to the elasticity of the production in the point of first-best investment.

Proposition 3 Third party decision making leads to first-best investment if the elasticity of the decision rule is equal to the elasticity of the production in the point of first-best investment.

The result that the elasticity of the third party's decision rule must be equal to the investment elasticity to reach first-best investment levels, circumstantiates the earlier claim that the arbitrator has to carefully balance the incentives of the contest. If, on the one hand, he applies a very elastic decision rule, the additional incentives might be too strong and persuade the parties to over-invest. On the other hand, if the arbitrator applies a rather inelastic rule, the investment levels might be below first-best. Therefore, it is important for the arbitrator to have expertise in the production technology in order to successfully calibrate the additional incentives which the verification contest sets.

\section{Noisy observability}

Besides the calibration problem, an arbitrator could also suffer from noise in his observability of the individual investment levels. To analyze this, assume that $\alpha$ describes the degree of noise in the arbitrator's observations of the investment levels, where $\alpha \geq 0$ (Amegashie 2006). If $\alpha=0$ then the arbitrator can perfectly observe the individual investments. Thus, a $\alpha>0$ means that the observability is noisy. The larger the degree of noise gets, the higher is the influence of chance in the arbitrator's decision.

$$
z(a, b)=\frac{a^{m}+\alpha}{a^{m}+b^{m}+2 \alpha}
$$

Taking this modified sharing function with noise and plugging it into the parties' profit functions leads to the following optimality condition for the investment level (see Additional file 1):

$$
\frac{\partial F}{\partial a}=\frac{\partial F}{\partial a^{\mathrm{US}}}-\frac{m}{2} \frac{a^{m-1}}{a^{m}+\alpha} F(a)
$$


In comparison with the optimality conditions with no noise (20), in the last term $1 /$ $a$ changed to $a^{m-1} /\left(a^{m}+\alpha\right)$. To analyze this change, the sensitivity of the fraction $a^{m-1} /\left(a^{m}+\alpha\right)$ in $\alpha$ is examined. If there is a very low degree of noise the fraction approaches:

$$
\lim _{\alpha \rightarrow 0} \frac{a^{m-1}}{a^{m}+\alpha}=\frac{1}{a}
$$

This matches the situation when observations are made in perfect conditions. However, the larger the degree of noise gets, the lower are the additional investment incentives the contest sets. If $\alpha$ becomes very large, the fraction $a^{m-1} /\left(a^{m}+\alpha\right)$ approaches:

$$
\lim _{\alpha \rightarrow \infty} \frac{a^{m-1}}{a^{m}+\alpha}=0
$$

This implies that the last term of Eq. (24) becomes zero and hence the investment levels under unanimous surplus sharing and under arbitration governance with a very high degree of noise are equal. This means that high noise in the observations of the third party cancels out the additional investment incentives the contest sets.

Proposition 4 If there is a very high degree of noise in the observations of the arbitrator, then arbitration governance fails to increase investment levels above the level of unanimous surplus sharing.

\section{Imperfect enforcement}

Another issue that could impair the effectiveness of arbitration is the possibility that the decision maker's award cannot be perfectly enforced. This means technically that the arbitrator is not able to distribute the whole surplus between the parties and that the parties have to unanimously share the remainder. If $\beta \in[0,1]$ is assumed to be the severity of the enforcement problem, then the sharing rule changes accordingly:

$$
z(a, b)=\beta \times 0.5+(1-\beta) \frac{a^{m}}{a^{m}+b^{m}}
$$

Taking this modified rule with imperfect enforcement and plugging it into the parties' profit functions leads to the following optimality condition for the investment level (see Additional file 1):

$$
\frac{\partial F}{\partial a}=\frac{\partial F}{\partial a^{\mathrm{US}}}-(1-\beta) \frac{m}{2 a} F(a)
$$

Comparing this optimality condition to the situation under perfect enforcement (20), one can see that the enforcement problem affects the additional incentives set by the contest. If $\beta$ becomes very low the investments approach the levels with perfect enforcement. However, if the enforcement problem increases, the last term of (28) approaches:

$$
\lim _{\beta \rightarrow 1}(1-\beta) \frac{m}{2 a} F(a)=0
$$

This means that the additional incentives set by the contest vanish and hence the investment levels will be the same as under unanimous surplus sharing. This intuitive result highlights the importance of the enforceability of the arbitrator's decision. If the decision award cannot be enforced at all, the joint venture's parties have to revert to unanimous surplus sharing. 
Proposition 5 If it is problematic to enforce the arbitrator's decision award, then third party decision making fails to increase investment levels above the level of unanimous surplus sharing.

\section{Lengthy proceedings}

The effectiveness of arbitration governance is also compromised when it takes a long time until a decision is reached. During such a lengthy proceedings the surplus of the joint venture is blocked and hence not accessible by the parties. This means that the period of time from investment in the joint venture to the payment of the surplus is relatively long. Investments with large gaps between investment and repayment yield smaller real returns than other investments with equal nominal returns but shorter maturity. Therefore, lengthy proceedings by the arbitrator harm the attractiveness of the joint venture investment and consequently cause under-investment.

In order to formally analyze the problem lengthy proceedings generate, assume that the parties discount future returns with the factor $\delta \in(0,1)$ (this could be e.g. the parties' financial costs) and that the length of the decision proceedings by the third party is denoted by $l$. Given these assumptions the parties' profit function becomes:

$$
\pi_{A}(a)=\delta^{l} \frac{a^{m}}{a^{m}+b^{m}} F(a, b)-a
$$

Maximizing this modified profit function leads to the following optimality conditions for the investment of the parties (see Additional file 1):

$$
\frac{\partial F}{\partial a}=\frac{1}{\delta^{l}} \frac{\partial F}{\partial a^{\mathrm{US}}}-\frac{m}{2 a} F(a)
$$

If the arbitrator's proceedings are not lengthy $l=0, \delta^{l}$ becomes 1 and hence the equation reflects the result under perfect conditions. To analyze the parties' investment decision as the length of the proceeding increases, the derivative of optimality condition with respect to $l$ is taken:

$$
\frac{\partial F^{2}}{\partial a \partial l}=-\frac{1}{\delta^{l}} \frac{\partial F}{\partial a^{\mathrm{US}}} \log (\delta)
$$

Since $0<\delta<1$ it follows that $\log (\delta)<0$. Given this and the assumption that the marginal investment is always positive $\partial F / \partial a>0$, Eq. (32) implies that if $l$ increases then the marginal product of investment increases as well. Because a larger marginal product of investment denotes a lower investment level, it can be concluded that as the arbitrator's proceedings get lengthier the parties invest less into the joint venture.

Proposition 6 If the arbitrator's proceedings to determine the sharing of the surplus are lengthy, then third party decision making fails to remedy the under-investment problem.

\section{Arbitration and the boundaries of meta-organizations}

The formal model in the previous section depicts the attributes - decision enforceability, latitude, information access, and fast decision making - as crucial for arbitration to effectively resolve disputes within meta-organizations and to induce optimal investment paths. These four attributes clearly distinguish alternative dispute resolution from ordinary courts and, therefore, indicate that arbitration is not simply a substitute to court proceedings. In this view a decision award is reminiscent of a board resolution, which executes the decision authority of the entire organization but at the same time seizes 
its factual power from the fact that it can be enforced in court if necessary. Thus, by the means of arbitration the meta-organization retains control over the resolution of internal conflicts because it autonomously selects the arbitrator and also determines the procedural rules of dispute resolution that are supposed to make the meta-organization sustainable over time.

Not only is the meta-organization free to choose the desired dispute resolution but also the appointed arbitrator has ample leeway. This latitude in the decision-making allows the arbitrator to decide in favor of what he believes are the business interests of the metaorganization. In an analogous manner the board of directors in a classical organization is only bound by basic internal rules and the rather fundamental rules of corporate law. The business judgment rule gives the board considerable discretion in defining the business strategy and hence preserving the organization's sphere of influence over time. In this respect, the latitude attribute indicates that arbitration lies within the power boundaries of meta-organizations and hence is a central element of the organizational architecture.

While enforceability and latitude concern the power boundaries of meta-organizations, information access and fast decision making, as further attributes of arbitration governance, are decisive for establishing the boundary of competence of a meta-organization (Santos and Eisenhardt 2005). Regarding the access to business information, arbitration reflects the attributes of a board of directors rather than of ordinary courts. The board of directors of a classical organization usually consists of managers with expertise in the industry of the organization, who are able to evaluate business-related information while judges in ordinary courts are legal experts. Expertise in the meta-organization's industry provides arbitrators with the competence to assess business-related information more accurately than only legal expertise would permit. Moreover, because of the confidentiality of arbitration the parties are able to share trade secrets and to use them for their argumentation. In front of an ordinary court this information, in contrast, cannot be presented as evidence since this would endanger the meta-organization's trade secrets. Therefore, the information competences of an arbitrator are quite similar to those of internal governance institutions, such as the board of directors. On the other hand, just like a public court the arbitrator has no direct control over the intellectual property rights of a meta-organization. That is different from a classical organization, where the board has not only access to all kinds of information but also may execute the residual right of control on pieces of information which are vested in patents, trademarks and the like.

Fast decision making, as the second attribute that relates to the meta-organization's competence boundary, pinpoints likewise that the function of third party decision making reflects the function of the board rather than of ordinary courts. While courts require time for their proceedings, the board of directors is able to pass resolutions at short notice. This allows the organization to adapt to changing conditions in a dynamic business environment. This competence of adaptability is seized by the meta-organization by the use of arbitration instead of relying on ordinary courts. The short-term decision making process of arbitration facilitates the fast resolution of internal conflicts and hence ensures that the meta-organization can quickly adapt to dynamic market conditions.

Discussing these four characteristic attributes shows that arbitration operates within the power and the competence boundaries of meta-organizations. Moreover, the comparison with the board of directors and with ordinary courts reveals more similarities 
with internal than with external governance institutions. Therefore, conflict resolution by arbitration can be considered as an internal governance device of meta-organizations.

While there are good arguments to assume that arbitration must be understood as an internal element of the organizational architecture of meta-organizations, it is another question what makes the role of the arbitrator so specific in a meta-organization compared to that of an arbitrator in an ordinary contractual relationship. The answer lies in the durability of arbitration aiming at making the meta-organization sustainable over time and to establish it as a firm. Or, to put it differently, the latent opportunism of underinvestment in the meta-organization's specific assets becomes counter-weighed by the latent monitoring of the arbitrator. Thus, the creation of unique resources in a metaorganization is backed-up by a contractual mechanism that is internal rather than external (Conner 1991, Foss 1996a,b).

In an ordinary contractual relation diverse contingencies may lead to disputes between the contractual partners that may be best solved by an arbitrator or an ordinary court. For those contractual disputes it is pivotal that they typically occur infrequently and that they usually terminate the contractual relation by sorting out the invested assets and accrued profits. That is different with regard to meta-organizations where a whole network of contracts is established and the purpose of the meta-organization is specified in less detail than in an ordinary business contract. Insofar as meta-organizations are more similar to a company where the business strategy, product portfolio etc. are also not specified in the corporate contract itself, but the business strategy is the result of the whole business activity over time. But apparently a meta-organization is also not a regular company with a clearly defined hierarchy, because it has no board that holds the whole bundle of residual property rights and can take decisions independently. Hence the coordination of assets remains the weak spot of meta-organizations.

Giving incentives for an optimal coordination of crucial assets is therefore the task of the arbitrator, who has himself no residual control rights in the meta-organization. But since a meta-organization is neither a creature of the market nor is it a hierarchy there is no possibility of coordinating assets via spot prices nor through decree. A way out of this dilemma is a contest by the arbitrator. The contest incentivizes on the one hand investments and on the other hand it rewards the parties according to their investment. Thereby the arbitrator has to access and assess information to prevent under- as well as over-investment. Thus it is the process of investment over time and the maintenance of business with which the arbitrator is concerned in the case of meta-organizations and not the resolving of assets and profits after a contract has failed. This specific role as a facilitator - instead of a mere solver of conflict - makes the arbitrator a core element of meta-organizations.

\section{Conclusion}

This paper argues that arbitration should be considered as an integral part of metaorganizations. This view shifts the analysis of third party decision making from mainly legal and contractual questions towards questions of organization design, such as how to position arbitration in the corporate governance structure and how to align it with the incentives of the organization. From that perspective, the paper applies a formal analysis to identify the relevant attributes of an arbitrator to become an effective decision making body. Thereby it becomes apparent that controlling the reward distribution 
function is a decisive element for the success of meta-organizations. In the process of controlling the reward distribution the arbitrator has to carefully set the incentive for contributing to the meta-organization. If he sets an incentive which is not strong enough, the parties will under-invest and the advantages of arbitration will vanish. Conversely, if the incentive the arbitrator sets is too strong, the parties will over-invest and thereby also deplete the profits of the meta-organization. However, as our analysis has shown the peril of over-investment seems to be rather small, because noisy observability (4.3), imperfect enforcement (4.4) and lengthy proceedings (4.5) create a drift towards underinvestment, which has to be overcome by a balanced investment contest initiated by the arbitrator. Thus, under-investment into the meta-organization's project is the most likely case.

The paper underpins its argument by focusing on joint ventures that use commercial arbitration to settle disputes between the parties. This example has been selected because joint ventures are very prominent for inter-firm collaboration. Commercial arbitration addresses the issue of cooperation better than other forms of third party decision making, and it is not surprising that it has become very appealing for dispute resolution. Moreover, in an international context, arbitration has several institutional advantages over ordinary courts such as no home country bias, enforcement according to the New York convention, greater latitude in decision making, and better observability.

While arbitration in international joint ventures is an illustrative example, it is not the only case in which third party decision making is used in meta-organizations. Every interaction between self-interested agents poses the risk of a dispute about tasks, performance and profit sharing. Meta-organizations are no exception, conversely, and they might be even more prone to fierce disputes due to their lack of formal authority. Therefore, it is not surprising that third party decision making has become an attractive governance mechanism for meta-organizations. Moreover new forms of organization (Puranam et al. 2014) use third party decision making to settle disputes between their members (c.f. O'Mahony and Ferraro 2007). The dispute resolution policy of Wikipedia, for example, formulates that third party decision making is required in the last stage of a dispute resolution process. There third party decision making assumes the form of an arbitration committee, whose members are third parties to the dispute but not to Wikipedia. ${ }^{13}$

Arbitrators in a meta-organization are third party to the dispute which they are resolving but this does not mean that they are necessarily third party to the organization itself. In this regard, it seems reasonable to consider the opposite, namely that arbitration, when adopted, is an integral part of the meta-organization. It is the glue that fixes the sometimes capricious contractual relations of meta-organizations when there is not only one locus of power. By the same token, arbitration is a vehicle to stabilize meta-organizations and to reap their specific benefits, while vertical integration or standalone production are only second best solutions in a globalized world with fragmented knowledge bases.

\section{Endnotes}

${ }^{1}$ An alternative classification for those complex organizational forms is hybrid organizations (Williamson 1991), in the sense that they play out between pure market transactions and vertically integrated firms. 
${ }^{2}$ Mother company of joint venture corporation shareholder (US) v. venture corporation shareholder (Mexico), Final Award, ICC Case No. 15248 in Albert Jan van den Berg (ed), Yearbook Commercial Arbitration 2013 - Volume XXXVIII, Yearbook Commercial Arbitration, Volume 38, Kluwer Law International, pp. 127 - 173.

${ }^{3}$ Ibid. p. 127.

${ }^{4}$ Limited Liability Company (Bahrain) v. Establishment (Saudi Arabia), Final Award, GCC Case No. 19XS/26/10/2006 in Albert Jan van den Berg (ed), Yearbook Commercial Arbitration 2013 - Volume XXXVIII, Yearbook Commercial Arbitration, Volume 38, Kluwer Law International 2013, pp. 63 - 79.

${ }^{5}$ Construction Company v Construction Company, Final Award, ICC Case No. 8528, 1996 in Albert Jan van den Berg (ed), Yearbook Commercial Arbitration 2000 Volume XXV, Yearbook Commercial Arbitration, Volume 25, Kluwer Law International, pp. $341-354$.

${ }^{6}$ Ibid. p. 341.

${ }^{7}$ First Investor, in liquidation (EU country), Second Investor (EU country) v Ministry of Agriculture (Non-EU country), Final Award, ICC Case No. 12112 in Albert Jan van den Berg (ed), Yearbook Commercial Arbitration 2009 - Volume XXXIV, Yearbook Commercial Arbitration, Volume 34, Kluwer Law International, pp. 77 - 110.

${ }^{8}$ Ibid. p. 77.

${ }^{9}$ For an extended discussion about the theoretical pillars of a comprehensive theory of the firm, see the controversy between Foss (1996a); Foss (1996b) and Conner (1991), Kogut and Zander (1992,1996) and Conner and Prahalad (1996).

${ }^{10}$ Since the arbitrator determines the distribution of the surplus in case of a dispute, the disagreement point $\left\{d_{A}, d_{B}\right\}$ for the Nash bargaining is given by his distribution decision. Given that the outcome of the Nash bargaining has to satisfy the condition $\max \left(x_{A}-d_{A}\right)\left(x_{B}-d_{B}\right)$ and that the third party assigns the whole surplus of the joint venture $F(a, b)=d_{A}+d_{B}$, it follows that the factual distribution of the surplus as an outcome of the Nash bargaining is equal to the distribution the arbitrator would determine in the case of a disagreement (i.e. $x_{A}=d_{A}$ and $x_{B}=d_{B}$ ).

${ }^{11}$ A special case is the situation if $m=0$, in this situation the third party's decision is perfectly inelastic which means that he awards always half of the surplus to each party irrespective of their investment levels. Since this mimics the situation of unanimous surplus sharing, it is not further considered in the remainder of the section.

${ }^{12}$ An $m=0$ would lead to a 50:50 sharing of the surplus irrespective of the levels of investments (see supra note 11). This exactly mimics the incentives under the non-arbitration regime and hence the investment levels would be equal in both cases.

${ }^{13}$ For the Wikipedia dispute resolution policy see https://en.wikipedia.org/w/index. php?title=Wikipedia:Dispute_resolution\&oldid $=673659518$ and for the Wikipedia arbitration committee see https://en.wikipedia.org/w/index.php?title=Wikipedia: Arbitration_Committee\&oldid=675583118 - accessed on November 11, 2015.

\section{Additional file}




\section{Acknowledgments}

We would like to thank two anonymous reviewers as well as the editor Phanish Puranam for their insightful comments on earlier drafts of this paper. We acknowledge also discussions of the paper at the seminars in Rotterdam, Siegen, Bologna and Paris, where we received valuable feedback from the participants. Maximilian Kerk gratefully acknowledges financial support from the Erasmus Trustfonds.

\section{Authors' contributions}

Both authors contributed equally to the article. Both authors read and approved the final manuscript.

\section{Competing interests}

There are no competing interests.

Received: 3 June 2016 Accepted: 25 January 2017

Published online: 07 March 2017

\section{References}

Aguilera RV, Desender K, Bednar MK, Lee JH (2015) Connecting the dots: Bringing external corporate governance into the corporate governance puzzle. Acad Manag Ann 9(1):483-573

Ahrne G, Brunsson N (2005) Organizations and meta-organizations. Scand J Manag 21(4):429-449

Amegashie J (2006) A contest success function with a tractable noise parameter. Public Choice 126(1-2):135-144

Antràs P (2014) Grossman-Hart (1986), goes global: Incomplete contracts, property rights, and the international organization of production. J Law Econ Org 30(suppl 1):i118-i175

Argyres N, Mayer KJ (2007) Contract design as a firm capability: An integration of learning and transaction cost perspectives. Acad Manag Rev 32(4):1060-1077

Baker GP, Gibbons R, Murphy KJ (2008) Strategic alliances: Bridges between "islands of conscious power". J Jpn Int Econ 22(2):14-163

Benson B (1999) To arbitrate or to litigate: That is the question. Eur J Law Econ 8(2):91-151

Casella A (1996) On market integration and the development of institutions: The case of international commercial arbitration. Eur Econ Rev 40(1):155-186

Chung T-Y (1996) Rent-seeking contest when the prize increases with aggregate efforts. Public Choice 87(1-2):55-66

Conner KR (1991) A historical comparison of resource-based theory and five schools of thought within industrial organization economics: do we have a new theory of the firm?. J Manag 17(1):121-154

Conner KR, Prahalad CK (1996) A resource-based theory of the firm: Knowledge versus opportunism. Organ Sci 7(5):477-501

Craig WL, Park WW, Paulsson J (1990) International chamber of commerce arbitration, Volume 1. Oceana Publications, New York

Foss NJ (1996a) Knowledge-based approaches to the theory of the firm: some critical comments. Organ Sci 7(5):470-476

Foss, NJ (1996b) More critical comments on knowledge-based theories of the firm. Organ Sci 7(5):519-523

Gibbons R (2005) Incentives between firms (and within). Manag Sci 51(1):2-17

Grossman SJ, Hart OD (1986) The costs and benefits of ownership: A theory of vertical and lateral integration. J Polit Econ 94(4):691-719

Gulati R (1995) Social structure and alliance formation patterns: A longitudinal analysis. Adm Sci Q 40(4):619-652

Gulati, R (1998) Alliances and networks. Strat Manag J 19(4):293-317

Gulati R, Puranam P, Tushman M (2012) Meta-organization design: Rethinking design in interorganizational and community contexts. Strat Manag J 33(6):571-586

Hart O (1995) Firms, contracts, and financial structure. Oxford University Press, Oxford

Hart O, Moore J (1990) Property rights and the nature of the firm. J Polit Econ 98(6):1119-58

Hirshleifer J (1989) Conflict and rent-seeking success functions: Ratio vs. difference models of relative success. Public Choice 63(2):101-112

Klein B, Crawford RG, Alchian AA (1978) Vertical integration, appropriable rents, and the competitive contracting process. J Law Econ 21(2):297-326

Kogut B, Zander U (1992) Knowledge of the firm, combinative capabilities, and the replication of technology. Organ Sci 3(3):383-397

Kogut, B, Zander U (1996) What firms do? coordination, identity, and learning. Organ Sci 7(5):502-518

Lumineau F, Eckerd S, Handley S (2015) Inter-organizational conflicts: Research overview, challenges, and opportunities. J Strateg Contract Negot 1(1):42-64

Lumineau F, Oxley J (2012) Lets work it out (or we'll see you in court): litigation and private dispute resolution in vertical exchange relationships. Organ Sci 23(3):820-834

Ménard C (1996) The economics of hybrid organizations. J Inst Theor Econ 160(3):345-376

Ménard, C (2013) Hybrid modes of organization. alliances, joint ventures, networks, and other strange animals. In: Gibbons R, Roberts J (eds). The Handbook of Organizational Economics. Princeton University Press, Princeton

Noussia K (2010) Confidentiality in International Commercial Arbitration. Springer-Verlag Berlin, Heidelberg

O'Mahony S, Ferraro F (2007) The emergence of governance in an open source community. Acad Manag J 50(5):1079-1106

Oxley JE, Silverman BS (2008) Inter-firm alliances: A new institutional economics approach. In: Brousseau É, Glachant J-M (eds). New Institutional Economics: A Guidebook. Cambridge University Press, Cambridge. pp 209-234

Puranam P, Alexy O, Reitzig M (2014) What's "new" about new forms of organizing?. Acad Manag Rev 39(2):162-180

Rajan RG, Zingales L (2000a) The governance of the new enterprise. In: Vives X (ed). Corporate governance: Theoretical and empirical perspectives. Cambridge University Press, Cambridge. pp 201-227

Rajan, RG, Zingales L (2000b) The tyranny of inequality. J Public Econ 76(3):521-558

Santos FM, Eisenhardt KM (2005) Organizational boundaries and theories of organization. Organ Sci 16(5):491-508 
Schanze E (1993) Symbiotic arrangements. J Inst Theor Econ 149(4):691-697

Schweizer U (1989) Litigation and settlement under two-sided incomplete information. Rev Econ Stud 56(2):163-177 Skaperdas S (1996) Contest success functions. Econ Theory 7(2):283-290

Stipanowich TJ (2004) Adr and the "vanishing trial": The growth and impact of "alternative dispute resolution". J Empir Leg Stud 1(3):843-912

Williamson OE (1991) Comparative economic organization: The analysis of discrete structural alternatives. Adm Sci Q 36(2):269-296

Zingales L (2000) In search of new foundations. J Financ 55(4):1623-1653

Submit your manuscript to a SpringerOpen ${ }^{\mathcal{D}}$ journal and benefit from:

- Convenient online submission

- Rigorous peer review

- Immediate publication on acceptance

- Open access: articles freely available online

- High visibility within the field

- Retaining the copyright to your article

Submit your next manuscript at $\gg$ springeropen.com 